\section{THE GENETICS OF SPECIATION}

Genetics and the Origin of Species

By Prof. Theodosius Dobzhansky. Second edition, revised. Pp. xviii +446. (Now York: Columbia University Press; London: Oxford University Press, 1941.) 28s. net.

$\mathrm{D}$ URING the last ten years geneticists have been getting to grips with the problems of evolutionary change; Prof. Dobzhansky describes the results of their work in this book. The first edition appeared in 1937, and it was reprinted two years later; but a second edition became necessary in 1941. These facts show clearly the great need for a book of this type. They also show how well Prof. Dobzhansky has filled that need.

Substantial additions have been made in the second edition, including one new chapter on "Patterns of Evolution", and reference is made to many original articles which have appeared since 1937. As before, one of the outstanding features of the book is the wealth of Russian material made available in English for the first time.

Genetics occupies a rather special place in experimental biology as it has always been concerned to a great extent with groups of individuals; indeed the laws of inheritance are most commonly used to define the statistical properties of such groups. This is, however, largely a reflection of genetical methodology since the older study of inheritance is at root the study of gene transmission from individual to individual and of gene action within the individual. Such a statement cannot be made about the newer development of population genetics. It is true to say that the genetical behaviour of a population depends ultimately on the behaviour of each constituent individual, but a new level of integration is reached because the population ean have properties not possessed by, and not always directly predictable from, the individual. The emphasis which Prof. Dobzhansky lays on this point is not the least of the services which he has rendered to the genetical study of evolution.

In proceeding to investigate these special properties of populations two main lines of approach have been used, each of which is itself composite. In the first place there is the genetical and cytological analysis of samples taken in the wild, from which conclusions may be drawn regarding the genetical structure of the population and by means of which its behaviour may be compared with that of other populations related both in time and in space. Secondly, there is the attempt to infer the behaviour of groups of organisms from the known properties of single individuals. In both of these enproaches genetics, cytology and statistical mathen:atics have played their parts in the past, and the ultimate understanding of population behaviour and of evolution depends on the successful combination of these various weapons in the future attack on the problems involved. Prof. Dobzhansky performs his second great service in bringing together the evidence which has already accrued in the different ways, in pointing out the conclusions to which this evidence leads and, perhaps most important of all, in exposing the deficiencies in our knowledge, while formulating working hypotheses which should help in guiding future attempts to fill these gaps.

If criticisms are levelled at the book, the most important will perhaps be that the advance on the older genetics is not greater. In following out the mechanism of inheritance, genes giving striking and easily identifiable effects were used of necessity ; but in Nature one is concerned much more with those characters which depend on the combined action of many genes each having a relatively small effect on the phenotype. Species differences are polygenic, and just as the progress from individuals to populations involves a new integration, the pro. perties and behaviour of polygenic characters are distinct from those of the so-called qualitative type used in the older genetical studies. It must, however, be said that Dobzhansky could have done little beyond directing attention to the necessity for a study of polygenic inheritance, for up to the present few investigations of this kind have been made.

A further point should be mentioned. The effect of population size on the spread and fixation of genes is discussed at some length, but it is not made clear that, inasmuch as the mating system, which may favour inbreeding or outbreeding of any degree of rigour, is always subject to genetical control of greater or less precision, the effective size of the population is itself a character on which selection will act and hence is adaptive. This must clearly have a profound influence on the interpretation which one places on the results of variation in apparent population size. Indeed, the whole notion of population size is rather vague unless a detailed knowledge of the breeding system is available.

The phraseology will seem to many to be somewhat unusual in a few places. In particular two mistakes, namely, the use of "indefinitely large" for "infinitely large" and the reference to the somatic number of chromosomes in polyploid wheat as the diploid number, are regrettable, because both are common errors which may have an extended life as a result of their unfortunate use in a book of such authority. These and their like are, however, minor blemishes and should cause the reader little trouble. "Genetics and the Origin of Species" is strongly to be recommended to all who, whether geneticists or not, wish to know how genetics can help in understanding evolution, and the extent to which it has already bəen used for this purpose. K. Mather.

\section{PSYCHOLOGY OF EVACUATION}

The Cambridge Evacuation Survey

A Wartime Study in Social Welfare and Education. Edited by Susan Isaacs, with the co-operation of Sibyl Clement Brown and Robert H. Thouless. Written by Georgina Bathurst, Sibyl Clement Brown, John Bowlby, G. A. Bullen, Nancy Fairbairn, Susan Isaacs, N. S. Mercer, Madeline Rooff, R. H. Thouless. (Contributions to Modern Education.) $\mathrm{Pp}$. ix +236 . (London: Methuen and Co., Ltd., 1941.) 8s, 6d. net.

HIS book deals too compactly with too much detail to admit of any adequate summary within the limits of a review. To stress some of the implications of its tit!e: it contains the findings of a team of experts, who, in organized co-operation, applied their special techniques of investigation to a local group of evacuated London children. The population under examination was therefore 